
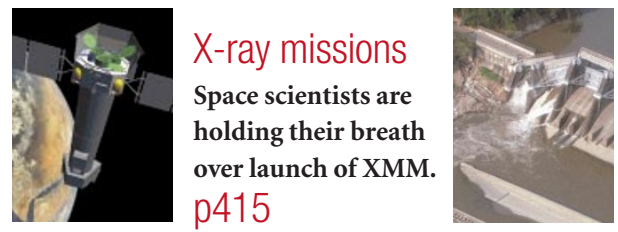

\title{
Taiwan
}

High-tech industries counts the cost of last week's earthquake. p416

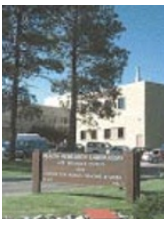
US energy labs Concern over the prospects for nonweapons research. p417

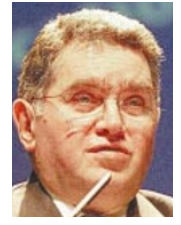

\section{Europe strengthens its hand in bioscience website talks ...}

Paris

The European Molecular Biology Organization (EMBO), upset over US plans to proceed unilaterally with plans for PubMed Central, a free website for life-science papers, is to provide 500,000 euros (US\$520,000) in seed money for the creation of E-Biosci, a European counterpart to be launched in the new year.

Discussions on proposals for a global lifesciences repository, led by both the US National Institutes of Health (NIH) and EMBO, shifted sharply during the summer when Harold Varmus, director of the NIH, decided to accelerate matters and push ahead alone with the launch in January 2000 of a US site that would accept both reviewed and unreviewed manuscripts.

PubMed Central, which is estimated to cost \$1-3 million each year, already has the backing of the American Society for Cell Biology, and the US National Academy of Sciences is considering whether to take part and on what terms. But some EMBO officials are unhappy at the US decision to create PubMed Central. "We would have preferred the joint launch of a harmonized world system," says one.

EMBO's planned European operation is not intended to be a competitor to PubMed Central, as this would defeat the purpose of making the literature freely accessible from a single repository. Rather, the EMBO council felt that Europe needs to invest - and quickly - if it is to have a say in the future development of a global repository.

Most of the seed money will go to creating the computing infrastructure at the European Molecular Biology Laboratory, which runs the European Bioinformatics Institute (EBI) in Cambridge, United Kingdom.

But EMBO will seek support from the European Commission, European scientific bodies and the private sector, as its pockets are not as deep as the NIH's, and PubMed Central has a head start in its links to the popular PubMed citation and abstract database, for which Europe has no equivalent.

Varmus visited EMBO this month to discuss ways forward. The US and European systems are expected to exchange material

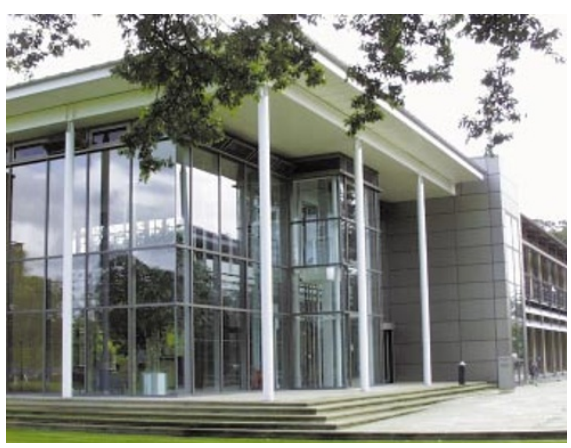

Key role: the European Bioinformatics Institute located at Hinxton Hall in Britain.

daily, much as happens now between genome databases at the NIH's National Center for Biotechnology Information and those at EBI - scientists accessing the system would be able to search seamlessly across one system.

The main difference between PubMed Central and E-Biosci is likely to be the content. In both systems, most of the peerreviewed content is expected to come from existing journals, but they will differ significantly in the manner in which non-peerreviewed material would be accepted.

PubMed Central would allow submissions from "any organization with at least three members who are principal investiga- tors on research grants from major funding agencies", whereas EMBO favours a system in which material is accepted from anyone but with all submissions being subjected to what it calls "light peer review".

EMBO is planning for the system to be administered by a mosaic of EMBO and other scientfic societies. Accepted papers will receive an EMBO stamp of approval (see Nature 400, 97; 1990). The principle of not accepting unreviewed preprints has gained the support of the Asia-Pacific International Molecular Biology Network (see Nature 400, 491; 1999).

It is still unclear whether the systems will coexist within the repository or whether common submission protocols will emerge. A determining step for both PubMed Central and E-Biosci could be the creation of an international governing body, as envisaged in the original E-Biomed proposal.

Such a body would address editorial and technical matters, as well as questions such as the terms under which commercial companies might be involved.

The United States is said to favour a governing body of eminent scientists, whereas EMBO is thought to prefer a structure comprising representatives of scientific societies, charities and organizations such as the Third World Academy of Sciences. Declan Butler

\section{... and India protects its past online}

\section{New Delhi}

India has launched a programme to create digital databases of its traditional knowledge - for example, of herbs with medical properties - that will be accessible to national patent offices in other countries, particularly the United States and Japan.

According to Ragunath Mashelkar, secretary to the Department of Scientific and Industrial Research, the move is intended to prevent foreigners taking out patents on such knowledge. India argued strongly for the protection of such knowledge at the recent ICSU/Unesco World Conference on Science in Budapest.
By establishing the existence of 'prior art', the databases are intended to prevent patents being granted for traditional Indian cures and remedies such as turmeric.

About two years ago, India successfully challenged the turmeric patent held by a US university (see Nature 389,6 ; 1997). But it has failed to prevent patents on 'basmati' rice (see Nature 391, 728; 1998) or, more recently, on an anti-diabetic substance from bitterguard, a plant traditionally used for food and treating diabetes.

Mashelkar says that documenting traditional knowledge in India will involve translating and digitizing 250 ancient texts, 
and examining thousands of scientific publications from the past 100 years or more. But the US\$1 million needed to create the database network is expected to save much more than that in the costs of contesting individual patents in foreign courts.

"We do not have the time or money to fight each patent," says Mashelkar. "The answer is to ensure that the patent is not awarded in the first place, by making databases of traditional knowledge available to patent examiners."

The Council of Scientific and Industrial Research has set up a unit in Pune, near Mumbai (formerly Bombay), to digitize traditional knowledge, and Mashelkar, who

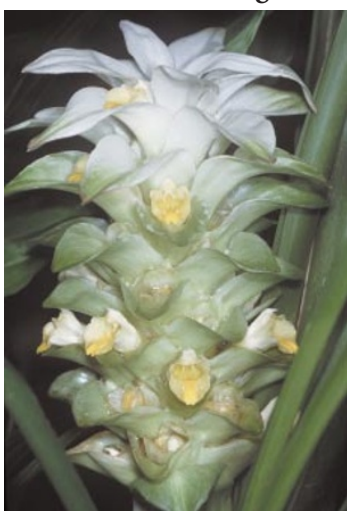

heads the

council, says

that the work

will be

completed in

one year.

He points out that the US

Patent and

Trademark

Office

(USPTO)

suggested to

India that it

Hands off: India blocked a US should create attempt to patent turmeric. the database. According to

USPTO, the turmeric patent might not have been issued if such a database had existed. In a letter to Mashelkar last month, USPTO official Robert Saifer admitted that the examiner who issued the patent "was not aware" of literature on the use of turmeric in wound healing in India.

K. S. Jayaraman
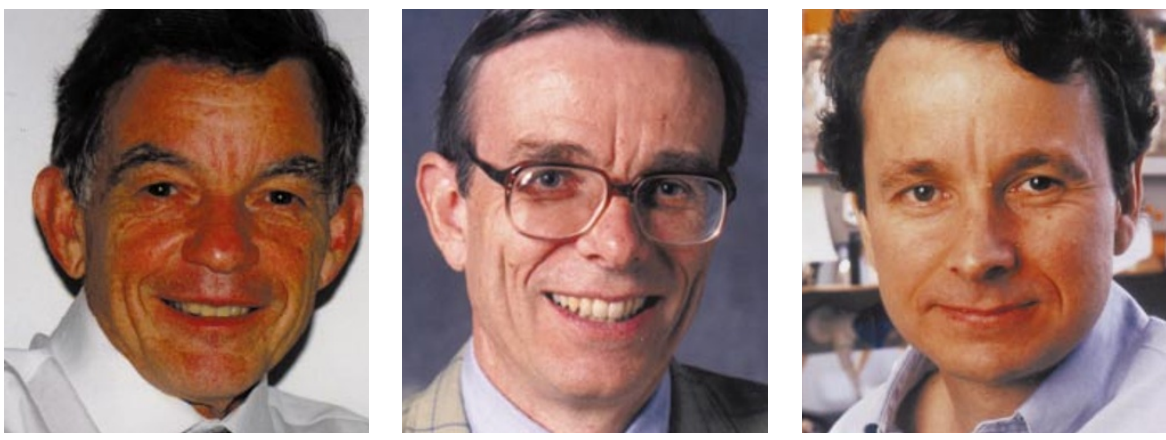

\section{Lasker awards honour three pioneers in ion channels}

\section{London}

Research that pioneered the understanding of electricity in biology was this week rewarded when three scientists shared the Albert Lasker award for basic medical research. Clay Armstrong of the University of Pennsylvania School of Medicine, Bertil Hille of the University of Washington, Seattle, and Roderick MacKinnon of the Rockefeller University in New York were recognized for their work on ion-channel proteins. Lasker awards are widely seen as highly significant, as many recipients subsequently win Nobel prizes.

Ion channels are holes in the membranes of cells that control the movement of ions, governing the electrical potential of membranes and intracellular signalling. They are basic to the body's electrical system, and control phenomena such as nerve impulses, muscle contraction and cardiac rhythm.

Armstrong was recognized for his work in elucidating the excitability of cell membranes and ion-channel gating. In the 1970s, Armstrong and Hille were among the few who believed that ion channels existed. Hille, who has worked for many years on various ion channels, is widely seen as one of the founders of this field. He showed that channels are independent physical entities within the membrane, and that they are selective to specific ions.

Potassium channels are among the most important molecules in the electrical signalling system. MacKinnon has been honoured for his work on the structure and function of these channels. $\mathrm{He}$ produced the first molecular description of an ion-selective channel. His 1998 paper in Science on the crystal structure of potassium channels was a crucial step forward for this field and sparked much new research.

Natasha Lode

\section{Coordinate international space science, meeting told}

\section{Munich}

Leading European space scientists have urged international space agencies to coordinate their research missions to ensure that they complement, rather than duplicate, each other.

At a meeting of the European Space Agency's (ESA) top-level science advisory committee and its science programme committee in Naples last week, scientists said that, apart from the Mars International Coordination Programme, cooperation between space-science disciplines is not as well established as it should be.

The committees, representing the astronomy, planetary-science and fundamental physics communities, met to discuss the scientific priorities for the ESA over the next decade. They noted that the major missions of the three largest space agencies are becom- ing increasingly similar.

For example, within less than a year, each will have launched X-ray observatories. The US space agency NASA's Chandra was launched in July, the ESA's XMM will launch in December (see opposite) and Japan's Astro-E will launch early next year. All three are also planning missions to Mercury.

The ESA's executive will consider ways of coordinating between disciplines, possibly at the level of the agencies' scientific advisory committees, to ensure complementarity of approach.

At the meeting, the ESA's executive said that the agency's science directorate will announce the opportunity for two mediumsized, 'flexible' missions in the coming weeks.

The executive also said that the ESA's next large, 'cornerstone' mission will be decided next June. The choice is between a journey to
Mercury, called Colombo, and an astrometry project called GAIA.

One of the two flexible missions, to be selected in a free competition next September, will probably be a contribution to the Next Generation Space Telescope, the NASA-led successor to the Hubble Space Telescope. Decisions about the second will be influenced by the choice of the next cornerstone mission, as the ESA aims for a balance between disciplines.

The science programme committee also approved the ESA's first technology mission, SMART-1, to be launched in November 2002. This will test electricpropulsion technologies for deep-space travel on a lunar mission. Small experiments will also fly on the mission, gathering X-ray and infrared spectroscopy data about the Moon's surface. Alison Abbott 